\title{
Da expansão dos mercados à metamorfose das economias populares
}

From the Expansion of the Market to the Metamorphosis of Popular Economies De l'expansion des marchés à la métamorphose des économies populaires

\section{Pedro Hespanha}

\section{OpenEdition}

\section{Journals}

Edição electrónica

URL: http://journals.openedition.org/rccs/390

DOI: $10.4000 /$ rccs.390

ISSN: 2182-7435

\section{Editora}

Centro de Estudos Sociais da Universidade de Coimbra

Edição impressa

Data de publição: 1 Março 2009

Paginação: 49-63

ISSN: 0254-1106

\section{Refêrencia eletrónica}

Pedro Hespanha, «Da expansão dos mercados à metamorfose das economias populares », Revista Crítica de Ciências Sociais [Online], 84 | 2009, colocado online no dia 01 dezembro 2012, criado a 19 abril 2019. URL : http://journals.openedition.org/rccs/390 ; DOI : 10.4000/rccs.390 


\title{
PEDRO HESPANHA
}

\section{Da expansão dos mercados à metamorfose das economias populares}

\begin{abstract}
Reconhecendo a existência, neste contexto de crise, de uma insatisfação generalizada perante um sistema económico e social cego perante as desigualdades sociais, insensível aos efeitos sociais da competição desenfreada e complacente com a delapidação dos recursos não renováveis, o artigo reflecte sobre a persistência de formas económicas distintas do sistema capitalista que com ele coexistem bem como sobre a emergência de movimentos e práticas sociais de resistência à lógica deste sistema, como é o caso das iniciativas de economia solidária, interrogando-se sobre o modo como elas podem servir de fundamento para uma mudança profunda de paradigma e, assim, contribuir para um sistema mais justo e capaz de adequar os recursos às necessidades e de maximizar o bem-estar humano e social.
\end{abstract}

Palavras-chave: Economia popular, economia solidária, racionalidade económica, sociologia económica.

\section{A economia do capital e as outras economias}

Por toda a parte, cresce a insatisfação com o sistema económico capitalista, designadamente pela sua variante neoliberal, pelas mais diversas razões: pela cegueira perante as desigualdades sociais, pela globalização excludente e insidiosa através das cadeias internacionais de produção, pela deslocalização do emprego à escala global, pela insensibilidade face aos "processos de destruição criadora” que esgotam precocemente os recursos, pelos custos sociais da desregulação laboral, pela delapidação dos recursos não renováveis, pela criação artificial de necessidades, enfim, pela "corrosão do carácter” dos próprios agentes económicos. Esta insatisfação dá lugar, muitas das vezes, a uma procura por soluções alternativas, à revalorização de práticas económicas baseadas noutros princípios que não a concorrência e o lucro, à imaginação de uma sociedade onde a separação radical entre a economia e o social seja substituída por modos de ajustar os recursos às necessidades de forma integrada e capaz de maximizar o bem-estar humano e social. 
Para pensar diferente é preciso começar por relativizar a teoria económica dominante, os seus pressupostos e as suas limitações, desconstruindo a sua imagem de única explicação possível para relações sociais de base material. E isso faz-se, desde logo, questionando a legitimidade do objecto da economia - os fenómenos ou factos económicos separados dos restantes aspectos da vida social.

As sociedades vivem e reproduzem-se por intermédio de relações muito complexas e de diferente natureza que apenas por abstracção e simplificação podem ser compartimentadas pelas disciplinas do conhecimento. São relações complexas no sentido em que nelas se misturam aspectos éticos e religiosos com aspectos políticos (desigualdades de poder, processos de dominação), com aspectos sociológicos (estruturação social, diferenciação social) e com aspectos económicos (produção, troca e distribuição de bens e serviços).

A disciplinação do objecto ocorre sempre que uma disciplina de conhecimento quer impor uma abordagem particular dos fenómenos e relações sociais, generalizando-a a todo o campo. Kenneth Boulding designou de imperialismo económico os esforços da teoria da escolha racional de Gary Becker para se impor também em outros campos das ciências sociais tais como o governo, as relações amorosas, a vida familiar ou a educação, não fazendo distinção entre o que é racional e o que é social na acção humana (Boulding e Tapan, 1972).

A "ciência económica" oficial (convencional, ortodoxa, institucionalizada, dominante, neoclássica) apresenta-se-nos hoje, portanto, como sendo a única forma legítima de conhecimento dos fenómenos e relações que designamos por económicas e alega que as outras ciências que aparecem a disputar o seu objecto apenas permitem explicar certas particularidades que escapam ao modelo interpretativo da economia, sem todavia o colocarem em causa. É como se houvesse uma legítima divisão de trabalho científico pela qual os economistas se concentram nas funções elementares da produção e do consumo, deixando às restantes ciências sociais as outras dimensões culturais do comportamento humano: dimensões morais, éticas, religiosas, políticas, etc.

Ora esta postura parece hoje claramente ilegítima. Primeiro, porque dentro da teoria económica também existem outros olhares sobre o económico que divergem radicalmente do modelo neoclássico. É o que se passa, por exemplo, com as correntes institucionalistas que reconhecem que o cálculo perfeito, a racionalidade auto-suficiente, os modelos cognitivos puros não existem. A economia é impura no sentido em que a sua racionalidade é limitada pelas "instituições, modos de pensar e de agir que os homens criaram para enfrentar a incerteza e o inesperado" (Reis, 2007). Segundo, porque a 
contribuição das outras disciplinas para o conhecimento dos fenómenos da vida social (a economia como "processo da vida) não é residual ou meramente instrumental dos modelos concebidos pela economia oficial (Cattani et al., 2008). Ao contrário, o reducionismo operado por estes modelos - e que se traduz, por exemplo, em considerar "irracionais" ou "perversos" os comportamentos distintos dos comportamentos típicos do bomo oeconomicus, como aqueles observados por Gregory King no século XVII sobre a elasticidade da oferta e da procura dos camponeses; ou em ocultar as limitações do conhecimento produzido pelos modelos econométricos pelo estabelecimento da condição ceteris paribus - tem vindo a ser compensado por contribuições teóricas decisivas de outras disciplinas.

Coube a Karl Polanyi a melhor formulação dos problemas que surgem quando não se consideram os processos de consolidação do capitalismo como sistema económico dominante e a sua articulação com os modos de produção, transformação e troca que ele dominou (Polanyi, 1944). Ao distinguir quatro princípios do comportamento económico que relevam de racionalidades diferentes - a domesticidade, a reciprocidade, a redistribuição e o Mercado - Polanyi ajuda-nos a compreender a pluralidade das formas económicas ao longo tempo e na actualidade. Como ele explica, a história e a etnografia conhecem várias espécies de economia.

Uma observação atenta permite-nos reconhecer nas sociedades contemporâneas a coexistência de, pelo menos, três formas de economia: a economia mercantil ou de mercado, a economia não mercantil de redistribuição (realizada pelo Estado) e a economia não monetária, baseada na troca simples de proximidade e na reciprocidade. Pode discutir-se o papel desempenhado por essas diferentes formas na reprodução do capitalismo mercantil, aceitar que o capitalismo tem uma capacidade inclusiva muito forte que lhe permite incorporar sistemas disformes, mas não pode dar-se de barato que elas não comportem riscos para o capitalismo, que não se possam transformar, sob certas condições, em factores de resistência e contradição que reduzam a sua funcionalidade para a reprodução do capital.

Abundantes estudos sobre o campesinato mostram que um sistema económico que nunca foi dominante em parte nenhuma pôde sobreviver durante séculos e manter o essencial da sua racionalidade: sobrevivência alargada das famílias em comunidade através de uma gestão prudente dos recursos e de uma solidariedade gerada por ameaças comuns. Uma espécie de economia moral, baseada no costume e na experiência passada, funciona como concha protectora e reduz os impactos desagregadores do sistema económico dominante, seja ele o feudalismo, o capitalismo ou o socialismo real (Lipton, 1968; Tepicht, 1973; Scott, 1976; Popkin, 1979). 
A desagregação das relações sociais baseadas na reciprocidade e na entreajuda solidária nunca foi completa e, por isso, os sistemas camponeses sofrem um processo de metamorfose mas resistem. O que se verifica com os sistemas camponeses pode estender-se sem grandes alterações às restantes formas de economia popular que partilham a mesma sociabilidade de raiz local, reforçada pelo interconhecimento, pela transparência de papéis e pela confiança, e se expressam em acções colectivas de carácter popular. É certo que as armas do sistema dominante são muito poderosas e passam muito por processos ideológicos de manipulação. No caso do capitalismo, o incentivo ao individualismo societal (ser free-rider) ou possessivo (ser proprietário), a desvalorização da confiança interpessoal ("amigos amigos, negócios à parte"), a instigação ao consumo irrestrito de bens materiais como via para a felicidade pessoal, são tudo instrumentos de domesticação da alteridade e de homogeneização dos comportamentos sob a égide da lógica de mercado.

Perante este quadro de forças contraditórias, a questão da autonomia relativa das formas económicas não capitalistas é uma questão em aberto sujeita a comprovação empírica. A persistência ou a emergência de movimentos e práticas sociais de resistência à lógica do sistema capitalista nos nossos dias, como é o caso das iniciativas de economia solidária - em particular aquelas mais organizadas e articuladas -, não se furtam ao risco de tais movimentos e práticas serem invisibilizados e se constituirem num "desperdício da experiência", mas bem ao contrário podem estar a servir de fundamento a uma mudança profunda de paradigma, solapando as condições de reprodução do sistema capitalista de mercado. Não sabemos, pois, se estes processos que se constituem em alternativas à economia padrão, como a economia solidária, serão capazes de desencadear uma transformação na sociedade, mas o facto é que tais processos não podem ser silenciados ou desperdiçados.

\section{Trajectórias das economias populares}

Sabemos como o capitalismo, para se implantar e consolidar, teve de destruir ou subverter as formas económicas que o precederam. Esse processo levou séculos e está marcado por acontecimentos que mudaram dramaticamente a vida das pessoas e das comunidades em que viviam, atacando as bases da sua reprodução económica:

- a expulsão dos camponeses dos seus territórios pelas leis sanguinárias dos enclosures em Inglaterra, rememorada por Marx no vol. 1 de O Capital; 
- a proletarização das famílias camponesas expulsas e a sua condição miserável de trabalho nas cidades inglesas da revolução industrial, retratada por Engels (em $A$ Condição das Classes Trabalhadoras na Inglaterra) e por Charles Dickens (em Hard Times);

- o controlo da autonomia e a progressiva submissão do trabalho artesão ao capital, exposta no Capítulo Inédito de $O$ Capital e louvada por Adam Smith em A Riqueza das Nações;

- a privatização progressiva dos bens comunais com base nos quais sobreviviam as populações camponesas, bem documentada no caso português na obra de Albert Silbert (1978);

- a desestruturação das economias locais pela expansão dos mercados do capital, um propósito que já encontramos bem presente nas Memórias Económicas da Academia das Ciências de Lisboa, dos finais do século XVIII, mas que tem prosseguido ininterruptamente até aos dias de hoje, com períodos de particular intensidade como o da integração europeia ou das imposições de ajustamento estrutural às economias em desenvolvimento que recorrem às ajudas do Banco Mundial ou do FMI.

Este processo de mudanças não se deu sem resistências e conflitos, que a memória também conservou. São as inúmeras revoltas camponesas desde os primórdios do capitalismo ao tempo presente; são as lutas do movimento operário desde o século XIX pelas condições de trabalho e remuneração; é o movimento anarquista contra o Estado e as instituições que amordaçam as liberdades e controlam os modos de vida; são os pensadores de esquerda, democráticos ou socialistas, que questionam a legitimidade política dos governos e instituições que promovem o capital, inspirando a formação de partidos com uma tal ideologia; é o movimento cooperativo e mutualista de origem operária que rompe com o colete de forças da organização empresarial do trabalho e estimula a associação dos estratos mais débeis da sociedade para a autosatisfação das suas necessidades.

Este processo da hegemonização da economia capitalista, pela destruição e subordinação daquilo que lhe era estranho, suscita uma questão importante de que gostaria de tratar nesta segunda parte: a da vitalidade e autonomia das formas que se lhe apresentam hoje como alternativas. Não irei abordar esta questão de uma forma sistemática e exaustiva, escrutinando os processos de resistência e de transformação das economias précapitalistas, recenseando os factores de desagregação ou de resiliência dessas formas, redefinindo os limites da sua autonomia face à lógica capitalista mercantil ou distinguindo o que nelas é ainda alternativo. Limitar- 
-me-ei a uma reflexão sobre as trajectórias de mudança das formas que mais resistiram ao capital e que eu designaria sinteticamente por economias populares, englobando assim as realidades camponesa e operária, as economias locais, o artesanato e pequena produção familiar, e o saber económico popular.

Procuro mostrar que, relativamente a este universo, as trajectórias se fizeram de acordo com duas estratégias principais: a primeira, no sentido da adaptação dos actores ao sistema capitalista de mercado, usando a posição detida na economia popular ou na economia informal como recurso; a segunda, no sentido de os actores manterem a sua posição na economia popular, usando o mercado e a economia informal como recurso. O que há de comum nestas estratégias é o facto de os actores jogarem simultaneamente em dois tabuleiros, assumirem comportamentos híbridos (quando não contraditórios) e estarem sujeitos a processos de reconfiguração identitária. Em qualquer dos casos, os resultados nem sempre correspondem às estratégias projectadas ou denotam uma alteração da estratégia face ao curso das mudanças. Por isso, é pertinente acrescentar uma terceira trajectória que tanto pode ter conduzido ao retorno dos agentes a uma condição de alternativa ao modelo capitalista quanto à reconversão capitalista da condição económica popular dos agentes.

A evidência empírica em que baseio as minhas reflexões resulta de estudos por mim realizados ou em que participei em Portugal, quer estudos passados sobre o campesinato e a pequena produção, quer estudos mais recentes sobre o desemprego e o mau emprego e sobre o empreendedorismo de pequeníssima escala (Hespanha, 1990, 2000; Hespanha et al, 1990, 2002a, 2002b, 2007; Sousa et al., 2007; Portela et al., 2008).

Começarei por analisar a economia destes microempreendedores para salientar que, de entre eles, se encontram presentes precisamente as duas estratégias mencionadas anteriormente e que, no decurso do processo de criação de um negócio ou empresa, a orientação estratégica pode mudar. Algumas implicações deste facto, que antecipo já como conclusão, são que o microempreededor não é forçosamente um capitalista em potência (ele pode ser um maximizador do bem-estar mas não necessariamente um maximizador do lucro), que é muito difícil ascender de microempreendedor à condição de grande empresário (porque o mercado se revela implacável perante um empreendedor que não maximize o lucro), que um pequeno negócio é quase sempre o resultado da cooperação de muita gente e que a experiência de alguém que montou um negócio pode ser extremamente útil para um empreendimento colectivo baseado na solidariedade. 
De seguida, darei uma atenção especial às pequenas actividades informais pela sua condição de patamar para empreendimentos mais consolidados e, finalmente, abordarei as formas colectivas de microempreendedorismo, norteadas por objectivos de cooperação e de solidariedade.

\subsection{A economia das microempresas}

As microempresas ou os pequenos negócios estão particularmente presentes em sociedades onde proliferem formas de pequena produção pouco ligadas ao mercado, movidas por uma racionalidade económica não lucrativa e desenvolvidas por pessoas com recursos limitados, como é o caso da sociedade portuguesa e, no âmbito europeu, a maior parte das sociedades sul-europeias. Basta atentar nos níveis elevados da actividade por conta própria nesses países (Portugal, 21\%; Espanha, 19\%; Itália, 29\%; Grécia, 32\%; contra UE25, $16 \%)^{1}$ e na preferência pelo estatuto de auto-emprego (Portugal, 62\%; Espanha, 56\%; Itália, 55\%; Grécia, 52\%; contra UE15, 45\%) ${ }^{2}$ para suspeitar que estamos perante situações que não correspondem ao modelo ideal de empresarialidade.

As estatísticas oficiais convencionaram designar por microempresas aquelas que ocupam até 10 pessoas. Elas representavam, no ano de 2005, $92 \%$ do total das empresas da UE, empregando $30 \%$ do total das pessoas e contando com $21 \%$ do total do valor acrescentado. Em Portugal, as microempresas do sector não financeiro ganham uma expressão ainda mais forte, representando $93 \%$ do total das empresas, a que corresponde $42,7 \%$ do total das pessoas empregadas e 30,6\% do valor acrescentado.

Segundo a mesma fonte, o número médio por microempresa era de 1,7 pessoas, e o peso das empresas com apenas uma pessoa era particularmente elevado em certos ramos de actividade (transportes e comunicações: $64,2 \%$; hotelaria e restauração: 64,6\%; comércio e reparações: 73,8\%; e actividades imobiliárias: $85,4 \%$.). Por sua vez as empresas até 4 pessoas representavam, no conjunto dos ramos de actividade $79 \%$ no total das microempresas.

Quando se analisam estas empresas e os seus empreendedores, o dado mais flagrante é que estes não partilham de todos os atributos do modelo típico da emprendeedorismo que a teoria económica padrão reconhece, ou seja a criação de valor (Say, 1821), a inovação e a mudança (Schumpeter, 1934), a procura de oportunidade (Drucker, 1985) e a desenvoltura na gestão e na previsão e assumpção do risco ou da incerteza (Knight, 1921).

\footnotetext{
${ }^{1}$ Eurostat, "SMEs and Entrepreneurship in the EU", Statistics in Focus, Industry, Trade and Services 24/2006 e "Key figures on European Business 2006", Statistical Pocketbook.

2 CE, Flash Eurobarometer: Entrepreneurship (June 2004)
} 
$\mathrm{Na}$ verdade, muitos dos negócios criados por indivíduos isolados ou por pequenos colectivos não obedecem a todos os requisitos da teoria: ou não geram valor por se situarem em ramos tradicionais de actividade; ou não representam nenhuma inovação em termos da gestão e do produto; ou não resultam de uma capacidade de detectar oportunidades, antes de uma opção induzida ou tomada como alternativa a uma outra menos viável como ter um emprego por conta de outrém; ou, finalmente, não evidenciam qualquer desenvoltura por parte do empreendedor, que se mostra muito apegado a uma forma de gestão rotineira e cautelosa.

A decisão de criar uma empresa - escolha do auto-emprego em detrimento do emprego por conta de outrem - pode resultar de um de dois tipos de impulsos de carácter económico: ou do aproveitamento de uma oportunidade de negócio ou da necessidade premente de obter um rendimento que não se afigura possível de outra forma.

Daqui a distinção clássica entre empreendedorismo de oportunidade, no sentido proposto por Schumpeter (1934), que engloba os indivíduos com capacidades empreendedoras que detectam uma oportunidade de negócio potencialmente lucrativo, traduzido por um maior conhecimento das tecnologias e/ou mercados, maiores capacidades de gestão, menor aversão ao risco ou outra característica pessoal que o torne mais atreito ao auto-emprego, e empreendedorismo de necessidade, englobando os indivíduos que, na ausência de oportunidades de emprego por conta de outrem ou, pelo menos, de postos de trabalho com características adequadas às suas competências específicas, optam pelo auto-emprego não por via da detecção de uma oportunidade de negócio mas antes pela ausência de alternativas mais favoráveis para a sua sobrevivência. Neste segundo caso, o indivíduo é empurrado na direcção do auto-emprego vendo este como um refúgio das condições desfavoráveis do mercado de trabalho.

De acordo com um estudo realizado (Portela et al., 2008), os microempreendedores tinham à partida situações bem diferentes quanto ao estatuto de trabalho e a ideia de negócio surgiu, nessas situações, com motivações diversas. Do ponto de vista do estatuto de trabalho, os microempreendedores estudados, por ocasião do surgimento da ideia de negócio, distribuiam-se pelas categorias de desempregados à procura de novo emprego, de desempregados à procura do primeiro emprego, de trabalhadores por conta de outrem, de trabalhadores familiares e de trabalhadores por conta própria.

Dentro da categoria dos desempregados à procura do primeiro emprego foi possível distinguir as situações daqueles que haviam perdido um emprego sem o desejarem e as de um abandono voluntário do emprego que se tinha. 
No primeiro caso, o auto-emprego foi considerado ora como um último reduto face à falta de emprego assalariado, ora como uma oportunidade de concretizar um desejo de trabalhar por conta própria, por se entender que está já reunida uma série razoável de condições (vg. saber e "calo" a par de certificação profissional, rede de "conhecimentos", ensejo de recorrer a apoios financeiros institucionais, etc.). No segundo caso, o abandono voluntário do emprego correspondeu a motivações também distintas, como conciliar a vida profissional com o cuidado dos filhos, fugir a um quadro de precariedade laboral e/ou de assédio moral no local de trabalho ou buscar autonomia na execução do trabalho e, assim, um maior nível de satisfação.

Do ponto de vista das motivações e em ambos os casos, pode detectar-se a presença quer de um empreendedorismo de necessidade quer de um empreendedorismo de oportunidade tal como foram anteriormente definidos.

Nos casos de desempregados à procura do primeiro emprego, a preocupação dominante foi achar, "agarrar" e manter uma alternativa à falta de emprego assalariado e manifesta claramente a presença de um empreendedorismo de necessidade. Dentre os microempreendedores que tinham uma condição de trabalhadores assalariados, é distinta a situação dos que criaram um negócio com a intenção de abandonar o emprego assalariado relativamente àqueles que o criaram sem essa intenção, procurando combinar as duas condições. $\mathrm{Na}$ primeira situação, as motivações foram buscar maior satisfação no trabalho e perceber que se tem as condições necessárias para "lutar" por conta própria, mas também detectar uma "oportunidade" de negócio e perceber que se tem as condições necessárias para a colocar em prática (vg. experiência e qualificação profissional, rede de "conhecimentos”, recursos económicos próprios, possibilidade de recorrer ao crédito bancário, etc.), ou seja, motivações conotadas tanto com a necessidade quanto com a oportunidade de empreender. Na segunda situação, a preocupação de combinar a condição de empregado com a de empreendedor resultou, num dos casos, de uma motivação solidária (aceitar o convite para liderar uma cooperativa de mulheres artesãs para as ajudar e, simultaneamente, contribuir para o desenvolvimento da região), em outro caso da vontade de ter um rendimento extra, para além do que é proveniente do trabalho assalariado e, num terceiro, do desejo de pôr em prática uma ideia de negócio antiga, mas sem querer largar a carreira que vinha construindo com o estatuto de trabalhador assalariado. Este último caso denota uma opção clara pelo empreendedorismo de oportunidade.

Existiam ainda situações em que os microempreendedores já trabalhavam em empreendimentos familiares ou em seus próprios empreendimentos. $\mathrm{Na}$ primeira situação, a criação de um novo negócio correspondeu ao desejo 
ou à necessidade de lograr autonomia face à família, coincidente com o momento de constituição da sua própria família; ou então, a um desejo firme de autonomia pessoal, a par de uma inclinação familiar forte. Mais uma vez a casuística mostra que a motivação oscila entre uma integração adversa e uma oportunidade de empreender. $\mathrm{Na}$ segunda situação, ou seja, quando se trata de criar um novo negócio quando já se tinha um antes, a motivação pode ser a expansão para outra actividade (vg. massagista free lancer que passa a querer vender produtos naturais e, por conseguinte, abre uma ervanária) ou o alargamento para uma actividade complementar, devido ao sucesso da primeira (passando a produzir o que antes apenas vendia ou a vender o que antes apenas se produzia para auto-consumo) ou subir mais um degrau numa trajectória bem sucedida (vg., encerrando um take away para, em seguida, abrir um restaurante de maiores dimensões), ou continuar a fazer o que se gosta de uma forma autónoma, ou ainda seguir um novo desafio quando o anterior negócio já não constituía uma fonte de realização pessoal. Em qualquer destes casos as motivações correspondem a um desejo de crescer pelo aproveitamento de oportunidades. No entanto, existem também motivações rivais como, por exemplo, fixar a actividade num espaço próprio de forma a melhorar as condições de trabalho ou ter maior autonomia abandonando o negócio anterior na sequência de desentendimentos com os sócios desse negócio. Nestes casos, a mudança não corresponde a uma compulsão a empreender, mas sim à resolução de um problema com a actividade que se tinha anteriormente.

Feitas as contas, de entre os 70 casos de microempreendedorismo estudados, as situações de orientação para a necessidade ou para a oportunidade têm uma expressão equilibrada, mesmo sabendo que nem sempre é fácil classificar as motivações. Isto basta para concluir que a diversidade nos microempreendimentos entra em choque com a concepção dominante de empreendedor e de empreendedorismo e que a variante do empreendedorismo de necessidade dificilmente passa no teste dos atributos exigidos por essa concepção.

Mas podemos ir mais longe e ver nestas diferenças não apenas uma questão de motivações mas sobretudo uma questão de racionalidade económica. Simplificando, de novo, preferimos admitir que alguns dos pequenos negócios se integram numa lógica económica típica da economia doméstica, da economia popular ou da pequena produção directa cuja racionalidade assenta num princípio de maximização do bem-estar e de reprodução económica do grupo, em vez de num princípio de maximização do lucro como a racionalidade capitalista de mercado. Indicadores favoráveis a esta hipótese abundam nos casos estudados: recurso a trabalho exterior à família, pago 
ou não pago, usando as redes de solidariedades primárias; informalidade total ou parcial nas relações de mercado, nas relações com as instituições e nas relações de comunidade; relativa indistinção entre a economia doméstica e a economia do empreendimento; recuo autárcico em períodos de crise, ambição limitada e primado da segurança.

Pode questionar-se inclusivamente em que medida o microempreendedorismo é um conceito adequado a definir estas práticas negociais movidas pela necessidade ou pela ambição limitada ou em que medida é que, usando o conceito de microempreendedorismo, estamos a desconsiderar dimensões dessas práticas que são verdadeiramente explicativas da sua existência, como o ethos de subsistência, a racionalidade de segurança ou a condição de modo de vida.

Não sendo assim o espírito empreendedor uma característica inata dos indivíduos, ele resulta sobretudo de uma socialização em ambientes de forte cultura empresarial e implica uma predisposição para correr risco. Por isso é mais fácil a alguns do que a outros tornarem-se empresários ou montarem um negócio por conta própria. De um modo muito esquemático, são aqueles empreendedores que emergem da economia popular - sejam pequenos produtores agrícolas ou artesãos, sejam operários pouco qualificados - que se afastam mais do modelo que a economia pretende estimular e apoiar, exactamente por estarem mais distantes daqueles ambientes.

\subsection{A economia informal}

A economia informal constitui um contexto muito favorável ao desenvolvimento de pequenos negócios e, mais do que isso, corresponde frequentemente a um período de consolidação desses negócios e a um estágio para a aquisição de uma prática de empreendedorismo, desembocando mais tarde no aparecimento de novas actividades no sector formal da economia.

A OIT define estas pequenas actividades no sector informal como unidades de produção de bens e serviços com o intuito primordial de gerar emprego e rendimento para as pessoas nelas envolvidas. Caracterizam-se pelo baixo nível de organização e a pequena escala, pela pouca ou nenhuma divisão entre trabalho e capital como factores de produção e pelo facto de as relações de trabalho, quando existentes, serem baseadas na maior parte das vezes em empregos ocasionais, relações de parentesco ou em relações pessoais ou sociais, em lugar de arranjos contratuais com garantias formais (OIT, 2006).

Os aspectos negativos destes empreendimentos informais são bem conhecidos por constituirem quase sempre o lado mais divulgado do fenómeno: o seu carácter ilegal (não conformidade com leis e regulamentos); o seu 
carácter fraudulento (não contribuirem para as receitas governamentais devido à evasão de impostos); o seu carácter de concorrência desleal (competem em desigualdade com empresas formais ao evitarem custos a que estas estão sujeitas); e o seu carácter eventualmente delitual (algumas actividades informais são criminosas ou ilegais, devido à evasão deliberada aos impostos).

No entanto, as actividades informais e, sobretudo, as de pequena escala são na maior parte dos casos a alternativa possível para muita gente, uma oportunidade de obtenção de rendimento para aqueles que de outra forma estariam sem meios de subsistência. Em vez de existir nessas pessoas uma espécie de preferência pelo informal, o que se verifica é que o informal é a sua escolha mais racional. Para quem tem falta de recursos (não só monetários, mas também educacionais ou sociais) a solução formal pode ser inviável. A incerteza acerca do êxito do negócio torna proibitivo e muito arriscado o investimento na formalização (autorizações, licenças, impostos) desse negócio. O sistema fiscal e de segurança social e as leis laborais são excessivamente restritivos ou complexos para um empreendimento de pequena dimensão. Por outro lado, não estando assegurada a clientela e sendo o ambiente comercial muitas vezes hostil para o início, crescimento e desenvolvimento de negócios, a passagem transitória por um período de informalidade é vista como como a melhor forma de reduzir o risco de não ter clientela e de não dominar o mercado. Finalmente, a falta de recursos materiais e de bens de propriedade limitam a responsabilidade e impedem o acesso ao crédito institucional, abrindo a porta ao crédito fiduciário das redes sociais primárias.

Apenas razões deste tipo explicam a insegurança e o risco suportados pelos empreendedores informais: multas fiscais, confisco, punição por delito económico, condenação por ilicitude, etc.

A reestruturação das economias e dos mercados de trabalho tem favorecido o recrudescimento das actividades informais mesmo nos países mais desenvolvidos. Existe hoje por parte dos governos a consciência de que essas actividades desempenham um importante papel de adaptação às situações de crise e, por essa razão, é feita acerca delas uma avaliação menos negativa. Em alguns países procura-se mesmo conferir alguma protecção ao sector informal sem o promover e, designadamente, proporcionar maiores incentivos às empresas informais, através da redução de custos e do aumento dos benefícios para se tornarem e permanecerem legais. Quem quer montar um pequeno negócio em geral não tem acesso a serviços de marketing, de formação em competências básicas ou de transferência de tecnologias. Uma orientação recente vai no sentido de tornar mais fácil o acesso a esses serviços e de ajudar à formalização das empresas. 


\subsection{A economia solidária}

Nesta categoria integram-se todas as formas de associação produtiva entre trabalhadores como alternativa ao desemprego, falta de rendimento e marginalização pelo mercado de trabalho. Situadas no domínio do que convencionalmente tem sido designado de autogestão e cooperação, estas formas caracterizam-se por um conjunto de princípios que as permite distinguir de outras modalidades de empreendedorismo. Dentre esses princípios, destacam-se: a autogestão e cooperação no trabalho, a participação, o igualitarismo, a auto-sustentação, o desenvolvimento humano e a responsabilidade social (Gaiger, 2004: 11). A sua filosofia é a da solidariedade e não a do dinheiro ou a do poder administrativo (Laville, 1994: 30).

A relação entre o lado solidário e o lado empreendedor destas iniciativas explica-se pela necessidade de novas modalidades de associativismo num período marcado pela globalização económica, o sistema das cadeias produtivas e a crise do sistema de trabalho assalariado, e pela preocupação de escapar ao desemprego massivo e à exclusão social dos trabalhadores a que estes factores têm conduzido sobretudo na periferia do sistema mundial. A saída empreendedorista representa uma valorização simultânea das vantagens da cooperação em torno de objectivos de melhoria das condições de vida e da eficiência económica para um uso mais adequado e flexível dos recursos, incluindo o trabalho.

A economia solidária tem vindo a desenvolver-se muito à escala mundial, mesmo em países desenvolvidos da União Europeia, como a França, a Itália, a Bélgica e a Espanha. A característica mais marcante é a pluralidade e novidade de formas: antigas e novas formas cooperativas e mutualistas, organizações sócio-caritativas, empresas sociais e solidárias, empresas auto-geridas e alternativas, iniciativas colectivas de alojamento, sistemas de trocas locais, comércio justo, instituições financeiras solidárias, produção-consumo e outras iniciativas rurais, empresas de inserção e outras formas de iniciativas de economia solidária dirigidas ou conduzidas por desempregados, mulheres, minorias étnicas e outras pessoas desfavorecidas social ou economicamente (ibid.).

Em regra, essas iniciativas mobilizam uma grande diversidade de recursos e, não raro, beneficiam de apoios importantes da parte das entidades públicas e, designadamente, das autarquias locais, precisamente pela capacidade que têm de encontrar uma saída para problemas que as políticas públicas convencionais não resolvem. A sua relação com a sociedade civil e com o Estado é, portanto, muito próxima, mas pautada por princípios de solidariedade e de reconhecimento mútuo. 
Em Portugal, o empreendedorismo colectivo e solidário é ainda muito débil, apesar de uma experiência muito rica havida na segunda metade dos anos 70 que conjugou os efeitos de uma crise aguda do sector empresarial (encerramento de empresas, descapitalização, abandono) com as aspirações dos trabalhadores a um modelo autogestionário. Actualmente as fórmulas associativas autónomas de produção de bens e serviços são claramente subalternizadas pelas entidades públicas na sua estratégia de promoção do microempreendedorismo, ao mesmo tempo que faltam outros apoios indispensáveis na sociedade civil que possam ajudar à concretização de projectos viáveis. Talvez por isso as microempresas em Portugal são dominantemente iniciativas de trabalhadores isolados.

Seja como for, as trajectórias típicas dos agentes da economia popular - ou seja, a conversão em microempreendedores individualistas, em trabalhadores ou empreendedores informais ou em empreendedores solidários - não prejudicam e deixam entender até uma estratégia comum para escapar a uma integração adversa na esfera capitalista de mercado.

Por isso, essas trajectórias são reversíveis no sentido em que os actores podem ter de recuar para reorientar as suas estratégias. Tal acontece frequentemente com quem se envolveu em negócios e os viu falhar por falta de condições para corresponder aos padrões de competitividade exigidos pelo mercado, por exemplo devido a uma aversão ao risco ou à indisponibilidade para dar resposta ao volume de trabalho que o mercado demanda.

É nestas situações que a saída para as fórmulas de produção colectiva ou solidária se podem tornar atractivas. Mas para tal é necessário que políticas adequadas apoiem e estimulem esta opção e que as organizações acautelem que o uso do trabalho na dependência do mercado não venha a gerar formas encobertas de proletarização.

\section{Referências bibliográficas}

Academia Real das Sciencias de Lisboa (1789), Memórias Económicas. Vol. I. Lisboa: Oficina da ARSL.

Boulding, Kenneth; Tapan, Mukerjee (1972), Economic Imperialism: A Book of Readings. Ann Arbor: University of Michigan Press.

Cattani, A.; Laville, J.-L.; Gaiger, L.I.; Hespanha, P. (orgs.) (2008), Dicionário Internacional da Outra Economia. Coimbra: Almedina.

Drucker, Peter (1985), Innovation \& Entrepreneurship: Practice and Principles. New York: Harper \& Row.

Gaiger, Luiz I. (org.) (2004), Sentidos e experiências da economia solidária no Brasil. Porto Alegre: Editora UFRGS. 
Hespanha, Pedro (1990), A propriedade multiforme. Um estudo sociológico sobre a evolução recente dos sistemas fundiários em Portugal. Coimbra: Faculdade de Economia (dissertação de doutoramento).

Hespanha, Pedro (2000), "Mal-estar, conflitualidade e violência no mundo rural português. A crise dos anos 90”, Revista Crítica de Ciências Sociais, 57/58, 25-51.

Hespanha, Pedro; Monteiro, Alcina; Ferreira, A. Cardoso; Rodrigues, Fernanda; Nunes, M. Helena; Hespanha, M. José; Madeira, Rosa; van den Hoven, Rudy; Portugal, Sílvia (1990), Entre o Estado e o Mercado. As fragilidades das Instituições de Protecção Social em Portugal. Coimbra: Ed. Quarteto.

Hespanha, Pedro; Damas, Ana; Ferreira, A. Cardoso; Nunes, M. Helena; Hespanha, M. José; Madeira, Rosa; van den Hoven, Rudy; Portugal, Sílvia (2002a), "Globalização insidiosa e excludente. Da incapacidade de organizar respostas à escala local”, in Pedro Hespanha; Graça Carapinheiro (orgs.), Risco social e incerteza: Pode o Estado social recuar mais? Porto: Afrontamento

Hespanha, Pedro; Portugal, Sílvia (2002b), A transformação da família e a regressão da sociedade-providência. Porto: Comissão de Coordenação da Região Norte.

Hespanha, Pedro; Caleiras, Jorge; Pessoa, Sandra; Pacheco, Vanda (2007), É o (des)emprego fonte de pobreza?. Porto: REAPN.

Knight, Frank (1921), Risk, Uncertainty and Profit. Boston: Houghton Mifflin.

Laville, Jean-Louis (dir.) (1994), L'économie solidaire. Une perspective internationale. Paris: Desclée de Brouwer.

Lipton, Michael (1968), "The Theory of the Optimizing Peasant”, Journal of Development Studies, 4, 327-351.

OIT (2006), A OIT e a economia informal. Lisboa: OIT.

Polanyi, Karl (1944), The Great Transformation: The Political and Economic Origins of Our Time. Boston: Beacon Press.

Popkin, Samuel (1979), The Rational Peasant. Berkeley: University of California Press.

Portela, J.; Hespanha, P.; Nogueira, C.; Teixeira, S.; Baptista, A. (2008), Microempreendedorismo em Portugal. Lisboa: INSCOOP.

Reis, José (2007), Ensaios de Economia Impura. Coimbra: Almedina.

Say, Jean Baptist [1821] (1963), A Treatise on Political Economy. New Jersey: Augustus M. Kelly Pubs.

Schumpeter, Joseph (1934), Theory of Economic Development. New York: Oxford University Press.

Scott, James (1976), The Moral Economy of the Peasant. New Haven: Yale University Press.

Silbert, Albert (1978), Le Portugal méditerranéen à la fin de l'Ancien Régime, XVIIIedébut du XIXe siècle. Lisboa: INIC.

Sousa, Liliana; Hespanha, Pedro; Rodrigues, Sofia; Grilo, Patrícia (2007), Famílias pobres: Desafios à intervenção social. Lisboa: Climepsi Editores.

Tepicht, Jerzy (1973), Marxisme et agriculture. Paris: Armand Colin. 